\title{
Framework for Developing a Mobile Augmented Reality for Learning Chemical Bonds
}

\author{
https://doi.org/10.3991/ijim.v13i07.10750 \\ Nor Farhah Saidin, Noor Dayana Abd Halim ( $\left.{ }^{凶}\right)$, Noraffandy Yahaya \\ Universiti Teknologi Malaysia, Johor. Malaysia. \\ noordayana@utm.my
}

\begin{abstract}
This paper presents the framework for developing a Mobile Augmented Reality (MAR) for learning Chemical Bonds, which is believed to reduce misconceptions among the students. Misconceptions always occur in classrooms, especially in science subject's which consist of abstract concepts. It is very important that these misconceptions be reduced, because they may affect the student's understandings of topics they have learned about. These may interfere with the student's education, and may also affect the student's performances afterwards. Visualization is one key approach that has been proven to help when seeking to improve the understanding of students, which has consequently led to a reduction in misconceptions. There are many technologies that have been integrated within education, and that show strong potential for producing visualizations. One of the recent popular technologies that have the potential for visualization is Mobile Augmented Reality. Mobile Augmented Reality has the ability to visualize abstract concepts through $3 \mathrm{D}$ images
\end{abstract}

Keywords-Mobile augmented reality, chemical bond, misconceptions, visualizations

\section{Introduction}

One of the electives science subject that less interested by students is Chemistry because students' found that Chemistry is hard to understand. Chemistry is actually the core to the others part of sciences that will equip the student with the knowledge that can help them to think critically and scientifically in order to find a solution while making decision and solving problems. According to Uzuntiryaki and Geban [1], students will fall in misconceptions when students have difficulties in understanding most of the concepts in chemistry which then will lead to prevention of meaningful learning.

There are several definitions of the terms 'concept' and 'misconception'. Eggen and Kauchak [2] have stated that an understanding of what happens around us through ideas, objects or events, is a concept. Misconceptions, on the other hand, can be described as ideas that provide an incorrect understanding of what happens around us. Misconceptions are also known as mixed conceptions, or conceptual misunderstandings [3]. 
Misconceptions are more complex and prevalent than simple misunderstandings, or the receiving of incomplete information [3]. There are multiple methods for arriving at misconceptions. They can occur as a result of a misunderstood vocabulary, or because of the result of combining several ideas into one [3]. Misconceptions also represent an important factor that affects learning. They can be acquired prior to enrolling in any school program, or they can be triggered at any stage of formal education [4].

According to Palmer [5], misconceptions among students have to be taken into account, because they can interfere with a student's learning of scientific principles and concepts. Therefore, the selection of teaching methods plays an important role in avoiding students' misconceptions [5]. There are many studies that have been conducted as a means of identifying students' misconceptions within the Chemistry field ([6], [7] \& [8]). The problem of misconceptions always occurs in regards to the topic of chemical bonds, because students have difficulty visualizing and understanding the related concepts [9]. As example in chemical bonding, students will tend to craft an alternative conceptions as students try to figure out the meaning from what is said by the teacher or what is written in the textbooks because the concepts of this topic is abstract [10].

Abstract concepts that consist in the topic of Chemical Bond cannot be directly applied to everyday life. Consequently, students faced difficulties in understanding the chemical bonding concept [1]. Based on the results of Sijil Pelajaran Malaysia, there are a lot of students still confused in answering simple questions regarding the topics of chemical bonding [11]. The common problem among the student is they cannot write the sequences of electron for the ionic bond and covalent bond and also difficult to create mental diagram about the formation of the bond [11].

Moreover, a conclusion has been made by Mohd Nor and Nur Afza [11] in their research that there are few problems in the study of chemical bonding that lead to the misconception among the students. The findings show that students still have difficulties in differentiating between ionic bond and covalent bond and cannot identify the conditions of every chemical bond that form between the elements. Besides, students also not confident in drawing the diagram of the electron sequences for the ionic compounds and covalent compounds which lead them to answer wrongly. Other than that, the problems in the topics of chemical bond that exist among the students are they cannot draw the Lewis structure in the right way because they faced difficulties in visualizing the abstract concept [11]. Therefore, students need visualization tools in order to build their understanding and help them to prevent the misconception.

It has been proven by Sanger and Badger that a visualization tool can positively affect students' conceptual understanding [12]. In the research by Taber [13], he suggests that school curriculum should include representations of science such as animations and videos. There is also research by Jones et al. [14], which found that many students are able to correct their misconceptions after viewing either static molecular visualizations or animations [14]. Visualization is significantly important, especially in Chemistry, because the subject involves atoms and molecules than cannot be seen by the naked eye, making visualizations important [15][16].

Vavra et al. [17] identified three important distinctions within the conceptualization of visualization objects. Visualization objects can be pictures, three-dimensional mod- 
els, schematic diagrams, computer-generated displays, simulations, animations, geometrical illustrations, videos, and so on. Objects can be displayed in a variety of media formats, including on paper, slides, computer screens, interactive whiteboards or videos, and some can be accompanied by sounds and other sensory data. Introspective visualizations are mental objects pictured by the mind. They can be considered imagined visualization objects. Interpretive visualization involves taking meaning from visualization objects or introspective visualizations, in relation to one's existing network of beliefs, experiences and understandings. This will then lead to the prevention of a misconception problem.

When visualization is utilized within Chemistry education, students can reflect on different concepts of Chemistry which they have learnt about during their learning process [15]. According to Nahum et al. [9], understanding many concepts and topics in Chemistry is essential because, recently, there have been difficulties regarding students' understanding of the concepts of Chemical Structure and Chemical Bonds.

There are many new technologies serving as visualization tools that have emerged, and that have a potential to be integrated in order to reduce misconceptions within sub topics, such as Chemical Bonds. An example of a particularly advantageous visualization tool is Augmented Reality (AR).

According to Shelton and Hedley [18], AR has a lot of advantages, and great potential for enhancing instructions and improving student understanding of complex concepts and contents. Therefore, these advantages can be applied to the topic of Chemical Bonds, in order to prevent misconceptions that result from students' inability to visualize bonding. Besides, AR also allows for detailed visualization and object animation, through which students can view and interact with the 3D images during learning processes [18]. This is because AR is displayed through different ways and angles of view, which enable students to understand the subjects better.

Based on meta-analysis from previous studies that have been conducted in regards to AR, there are many applications that have been developed within several fields, but are not limited to education. However, the number of studies and applications of Mobile Augmented Reality (MAR) are still low. According to FitzGerald et al. [19], the use of AR in education, particularly within mobile learning, is still in its earliest phase. This is still a phase of changing and improving, but studies have shown that AR can be used successfully within constructivist learning, that involve collaboration and student inquiries. Collaborative learning is claims one of the most effective learning strategies in polishing students' communication skills and also providing supportive environment for student [20]. Besides, it seems possible that mobile phones can be used in learning processes, as only a small percentage of students do not own or use mobile phones [21]. According to Chee et al. [22], the smartphones is currently the most widely devices that been used in mobile learning which this proven that mobile phone is relevances to be use in learning process.

Furthermore, mobile phone/tablet computing is associated with a higher degree of comfort and familiarity, with the size and practically of the technology making it more portable than laptops. This fact is supported by research conducted by Oostveen et al. [23], in which students tended to frequently bring tablet PCs to class. Mobile 
technology also shows a positive outcomes and proven can motivate the students to actively engaged in learning [22][24].

Therefore, the main objective of this research is to develop a MAR application that will help students to visualize abstract concepts within the topic of Chemical Bonds. This may lead to the prevention of misconceptions within student learning processes in regards to the particular topic, and will also encourage students to learn in a way they prefer. However, in order to make sure that the process of developing the MAR is undertaken in parallel with research objectives, a proper framework is referred to as a guideline. Thus within this research, there is a cognitive theory of multimedia learning [25], and the principles for developing visualizations tools within the field of Chemistry [26] are being followed.

\section{The Cognitive Theory of Multimedia Learning}

Multimedia presentations represent an effective means of delivering information to learners, regardless of whether they prefer visual presentations or verbal presentations, as illustrated by Mayer and Moreno [27]. Therefore, multimedia has been recognized as a good medium for delivering information. Besides, Mayer and Moreno [27] have also stated that the multimedia instructional environment has been widely recognized as one that has great potential for improving learning processes. Figure 1 presents the framework of the Cognitive Theory of Multimedia [25]. There are four phases within the theory, which include multimedia presentation, senses, working memory and long-term memory.

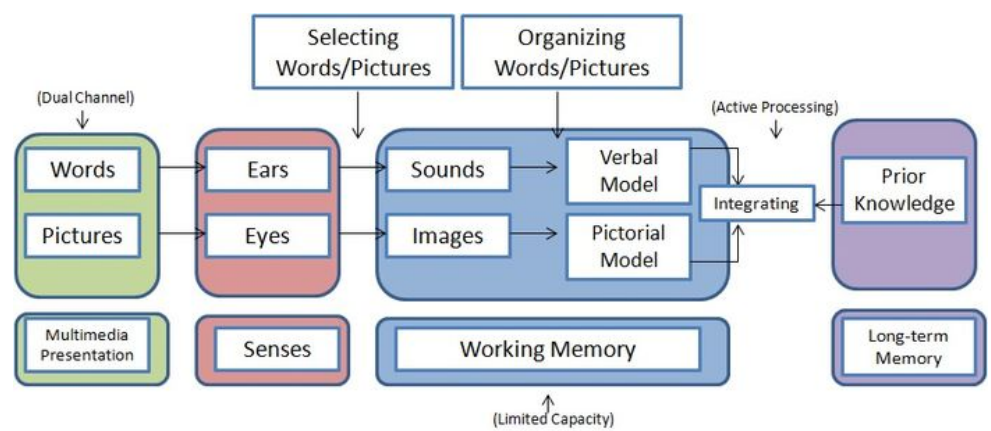

Fig. 1. The Cognitive Theory of Multimedia [25]

In Mayer [25], there is statement regarding how cognitive theory contributes to the suggestions of Multimedia Design Principles. There are three assumptions in regards to how people learn through the use of pictures and words. The first assumption is that of the dual channel assumption in that there are two channels including the visualpictoral channel and the auditory-verbal channel ([28] \& [29]). The next assumption is the limited capacity assumption, in which each channel has a limited capacity for holding and manipulating information ([28 \& [30]). Lastly, the third assumptions is the active processing assumption, which is that meaningful learning is believed to 
occur when learners have an active processing relationship with the channel, and are involved in the process of selecting pictures and words, organizing them and integrating them, utilizing the prior knowledge that they possess [31]. The Cognitive Theory of Multimedia Learning evolved from these three assumptions, and was introduced by Mayer [25]. Several principles were highlighted by Mayer which have been taken into consideration during the designing and development of meaningful multimedia learning [32].

Table 1 shows the five principles that have been highlighted by Mayer, and have been utilized when designing and developing meaningful multimedia learning [32]. There were other principles mentioned by Mayer, but only five main principles are highlighted [31]. This study is about designing and developing the MAR, which uses multimedia tools within the Chemical Bond topic. In addition to considering the guidelines involved in designing and developing a meaningful multimedia learning tool, the principles for designing Chemistry education tools have also been considered. This is because different subjects require different strategies for designing and developing visualization tools. Therefore, this paper suggests the use of the Principles for Designing Visualization Tools in Chemistry as outlined by Wu and Syah [26].

Table 1. Five Multimedia Principle [32]

\begin{tabular}{|l|l|}
\hline \multicolumn{1}{|c|}{ Principles } & \multicolumn{1}{c|}{ Descriptions } \\
\hline Coherence Principle & $\begin{array}{l}\text { People learn better when extraneous words, pictures and sounds are ex- } \\
\text { cluded, rather than included. }\end{array}$ \\
\hline Signaling Principle & $\begin{array}{l}\text { People learn better when cues that highlight the organization of the essen- } \\
\text { tial material are added. }\end{array}$ \\
\hline Redundancy Principle & $\begin{array}{l}\text { People learn better from graphics and narration compared with a combina- } \\
\text { tion of graphics, narration and on-screen text }\end{array}$ \\
\hline Spatial Contiguity Principle & $\begin{array}{l}\text { People learn better when corresponding words and pictures are presented } \\
\text { closer, rather than further apart on a page or screen }\end{array}$ \\
\hline Temporal Contiguity Principle & $\begin{array}{l}\text { People learn better when corresponding words and pictures are presented } \\
\text { simultaneously, rather than successively }\end{array}$ \\
\hline
\end{tabular}

\section{The Principles for Designing Visualizing Tools in Chemistry}

The design stage is important for the development of multimedia tools for teaching and learning. Every tool that has been developed has followed certain criteria, which must be considered in order to make sure that the developed tools really make sense, and can achieve their objectives. Shariffudin et al. [33] has stated that the methods used for designing learning materials, and the pedagogical aspects of teaching and learning, have to be taken into consideration before development processes are undertaken. AR is one of the learning materials which act as visualization tools, which may aid teaching and learning processes. Therefore it is important to properly design the AR before developing it. Within this research, AR is utilized in the form of a MAR, applied as a visualization tool that assists in the process of learning about Chemical Bonds. The designing of the MAR, regarding to Chemical Bonds, has involved the consideration of several important concepts in order to ensure that the learning pro- 
cess regarding the particular topic is smoother. This is because students have varying abilities to visualize concepts.

Table 2 below presents the details on how the implementation of the Cognitive Theory of Multimedia Learning and Table 3 presents the details on how the implementation of Principles for Designing Visualizing Tools within the Chemistry field on designing MAR for learning Chemical Bond.

Table 2. The implementation of Cognitive Theory of Multimedia Learning on designing the MAR.

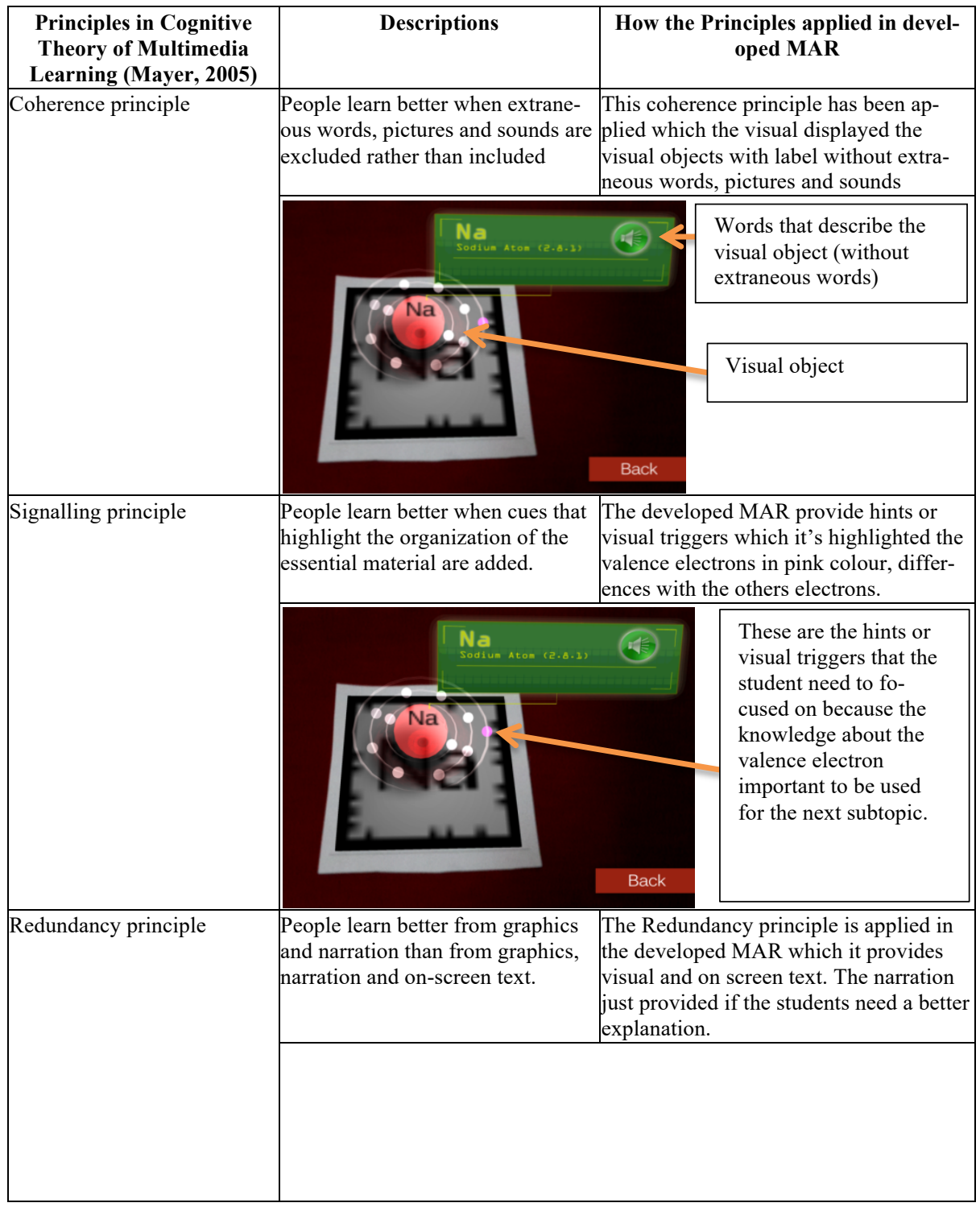




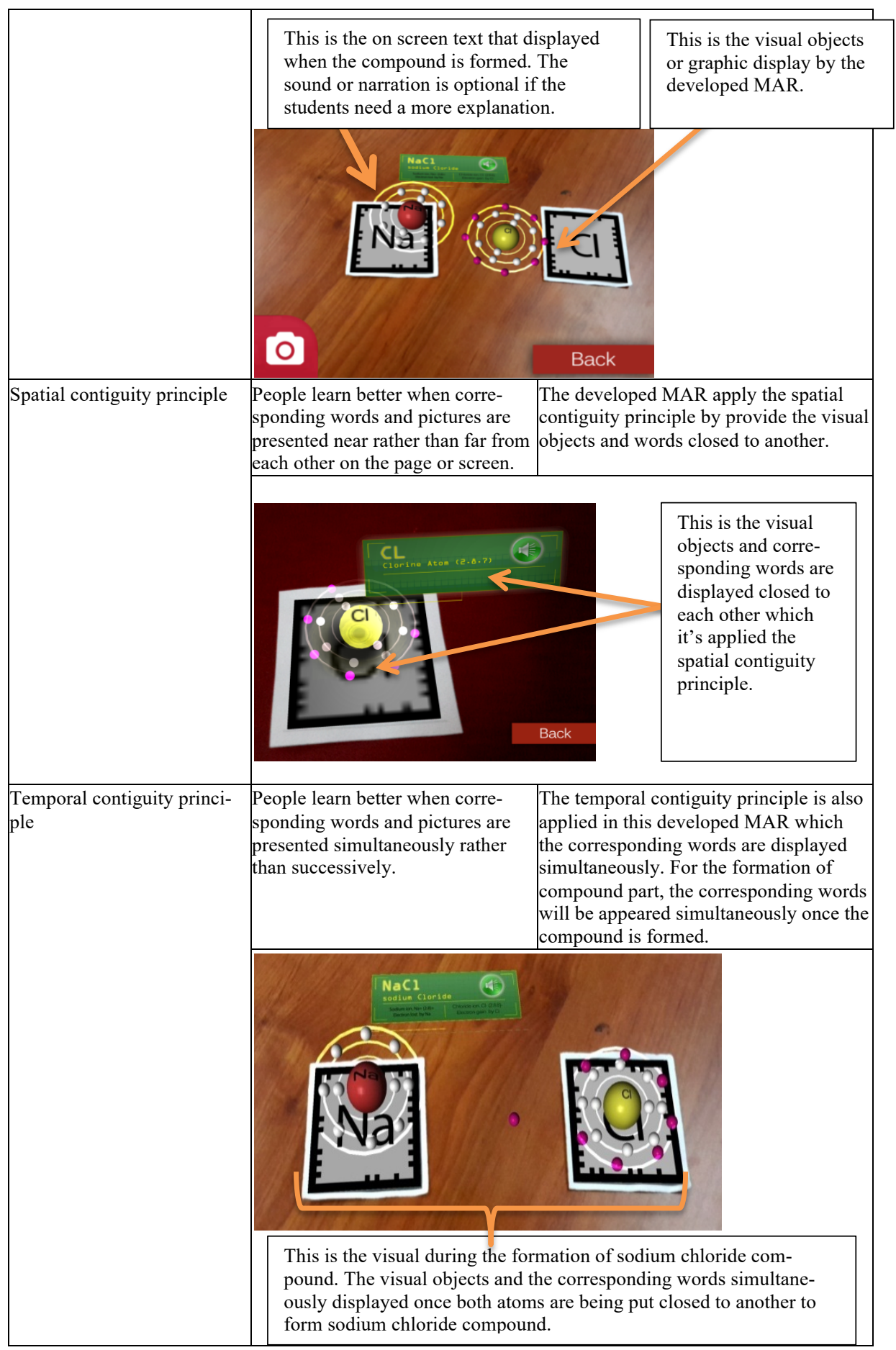


Table 3. The implementation of the Principles for Designing Visualizing Tool on Chemistry (Wu \& Syah, 2004) in designing the MAR

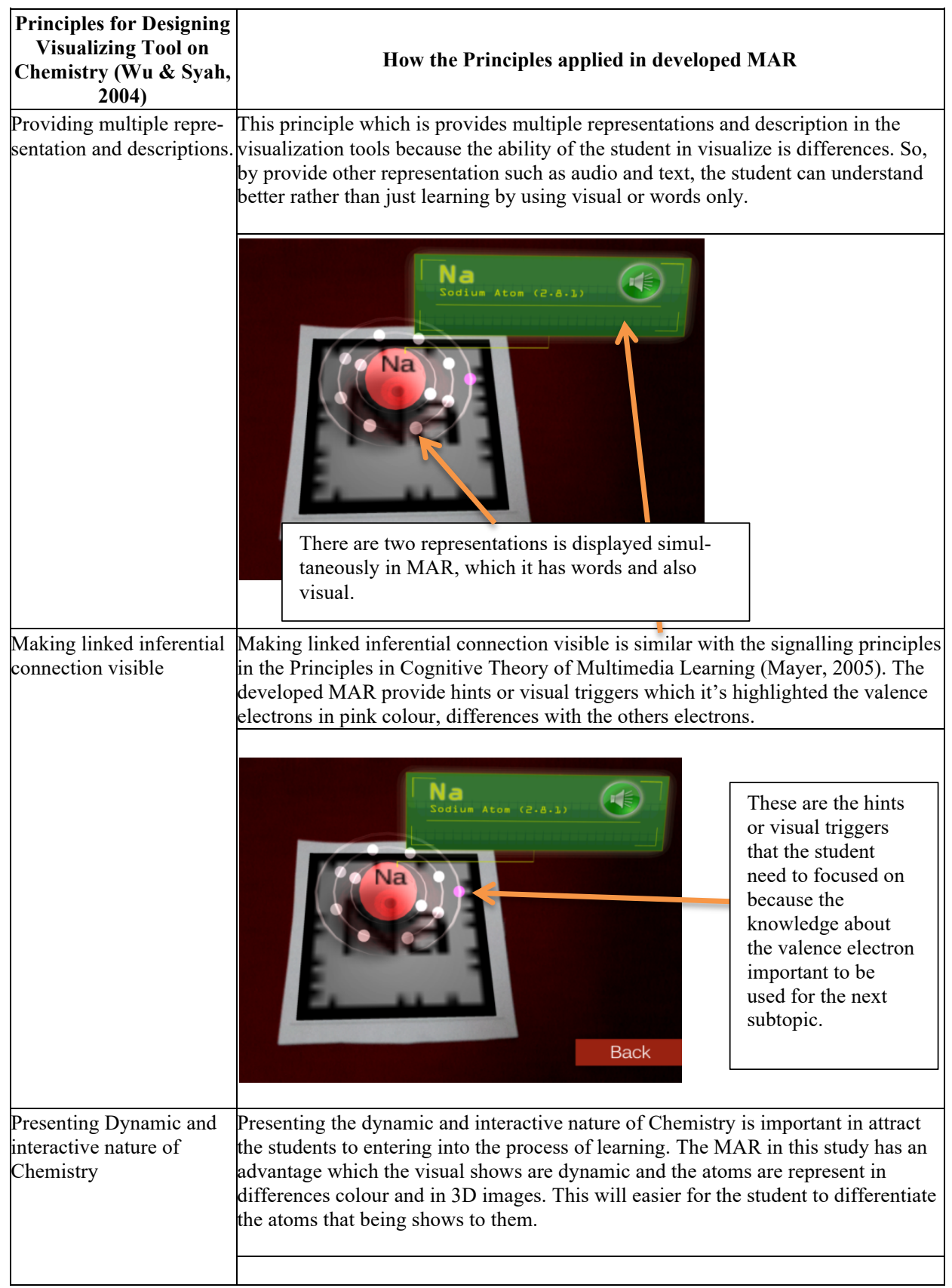




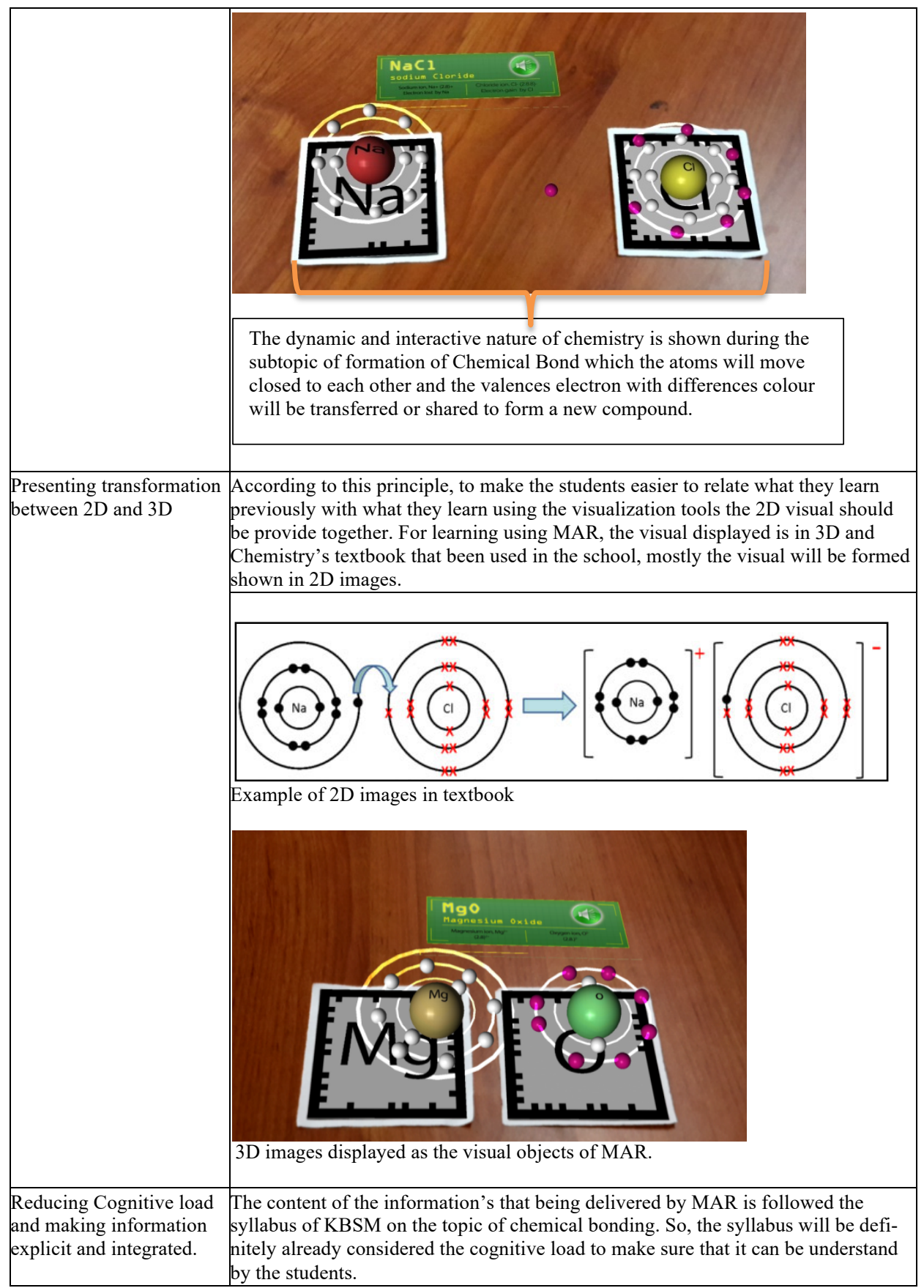

This research has designed the MAR learning environment based on these two principles as discussed above. Once the MAR is successfully designed, meaningful 
learning will take place, and this will have a positive impact on the achievements of students. In regards to this study, the MAR has been developed and the effects of the developed MAR on students' achievement in the topic of Chemical Bond are being investigated. The methodology has been describes in the Methodology part.

\section{$4 \quad$ Methodology}

To investigate the effects of the developed MAR on student's achievement on the topic of Chemical Bond is the objective of the research. Thus, the Pre and Post Test on the topic of Chemical Bond are being conducted. After about 4weeks treatment using MAR, the Post Test is being given to the students to be answered. The Test is consists of 3 parts which are the objectives questions in Part A, structured questions in Part B and essay questions in Part C.

\subsection{Sample}

The samples are involved 16 students in Form 4 who taking chemistry subject in secondary school at Johor Bahru. The students that selected are the students who have skills in using technologies and already exposed with latest learning technology such as online learning, mobile learning and others.

\subsection{Data analysis}

The data were analyzed using the Statistical Package for the Social Sciences (SPSS). There is descriptive analysis and inferential analysis was being conducted in the analysis part of the research.

\subsection{Descriptive analysis}

The scores of each student were being computed and student's achievement were analyzed and compared between the two tests that conducted which are the Pre and Post for Chemical Bond. The comparison for minimum scores for the Pre Test for Chemical Bond Test is 10 (39-29) while for the Post test the comparison between minimum and maximum scores are 13 (71-58). The mean score for the Pre Test is 41.69 with a standard deviation of 9.070. The mean score for the Post Test is 52.45 with a standard deviation of 9.638. The mean for the Post Test is higher than the mean of Pre Test. It shows that, on average that scores in the Post Test is higher than the scores in the Pre Test. The mean differences of the mean percentage of the Pre and Post Chemical Bond Test are $10.76 \%$. The details descriptive analysis for each test is shown in Table 4. 
Table 4. Descriptive statistics for pre and post chemical bond test

\begin{tabular}{|l|c|c|c|c|c|}
\hline \multicolumn{1}{|c|}{ Type of test } & N & Min & Max & Mean Percentage & Std. Deviation \\
\hline Pre Chemical Bond Test & 16 & 29 & 58 & 41.69 & 9.070 \\
\hline Post Chemical Bond Test & 16 & 39 & 71 & 52.45 & 9.638 \\
\hline
\end{tabular}

\subsection{Inferential analysis}

Instead of the descriptive analysis, the inferential analysis also conducted. This inferential analysis is conducted to compare the means between the two groups of variables which is the pre chemical bond test and post chemical bond test. However, nonparametric test have to be performed as alternatives to the parametric test because the number of sample is not enough to run the parametric test. Thus the non-parametric test of the Wilcoxon Signed-Ranks Test is used to investigate whether there is a significance difference between the Pre Test and Post Test scores.

The Wilcoxon Signed-Ranks Test (Wilcoxon Test) is been used to compare the mean scores between both test. The hypotheses involved were:

- $\mathbf{H}_{\mathbf{0}}$ : There is no significance differences between the mean of the Pre Test scores and the Post Test scores in Chemical Bond Test.

- $\mathbf{H}_{1}$ : There is significance differences between the mean of the Pre Test scores and the Post Test scores in Chemical Bond Test.

Table 6 below shows the ranks for Wilcoxon Test and "a" in the table is refer to the number of observations or number of students $(\mathrm{N})$ with Post Test scores lower than the scores in the Pre Test. "b" refers to the $\mathrm{N}$ with Post Test scores greater than the scores in the Pre Test and "c" refers to the $\mathrm{N}$ with Post Test scores equal to the score in the Pre Test. This mean none students have scores in the Post Test lower than the Pre Test (Negative Ranks). 15 students have scores in the Post Test greater that the Pre Test (Positive Ranks) and only one student have the same score in both Pre Test and Post Test (Ties).

Table 5. Ranks for the Pre Test and Post Test

\begin{tabular}{|l|l|c|c|c|}
\hline \multicolumn{5}{|c|}{ Ranks } \\
\hline \multirow{4}{*}{$\begin{array}{l}\text { Pre Chemical Bond Test } \\
\text { Post Chemical Bond Test }\end{array}$} & Negative Ranks & $0^{\mathrm{a}}$ & .00 & .00 \\
\cline { 2 - 5 } & Positive Ranks & $15^{\mathrm{b}}$ & 8.00 & 120.00 \\
\cline { 2 - 5 } & Ties & $1^{\mathrm{c}}$ & & \\
\cline { 2 - 5 } & Total & 16 & & \\
\hline
\end{tabular}

The result in Table 7 below shows that the values of Wilcoxon Test where "d" refers the value based on the negative ranks. The significant value, 0.001 , is lower than the value of alpha, .05, thus the Ho is rejected. This means that the Pre Test scores have a significant difference from the Post Test scores $(z=-3.412, p=0.001)$. These 
results suggest that MAR have a significant in improving the achievement of the students in the topic of Chemical Bond

Table 6. Wilcoxon Signed-Ranks Test Statistics of the Pre Test and Post Test for Chemical Bond

\begin{tabular}{|l|c|}
\hline \multicolumn{2}{|c|}{ Test Statistics $^{\mathrm{a}}$} \\
\hline Z & Pre Chemical Bond Test - Post Chemical Bond Test $^{\mathrm{a}}$ \\
\hline Asymp. Sig. (2-tailed) & $-3.412^{\mathrm{d}}$ \\
\hline
\end{tabular}

\section{Conclusion}

In conclusion, misconceptions are common problems that are faced within today's learning processes, especially in science education that often involves abstract concepts. Visualization is one of the proposed ways that has the potential to reduce misconceptions. One tool with proven visualization advantages is the MAR. However, in order to achieve the objectives which is to develop the framework for developing a Mobile Augmented Reality (MAR) for learning Chemical Bonds, certain principles and theories should be followed. The Cognitive Theory of Multimedia Learning (CTML) [25] proposed within this study will be a good source of reference, because the MAR developed accordingly consists of words and pictures. Additionally, 'The Principles of Designing Visualization Tools in Chemistry' by Wu and Syah [26] also provides strong principles that have to be taken into consideration, as this research focuses on Chemical Bonds. Therefore, the research framework is important in studies, in making sure that the process of designing and developing meaningful multimedia learning tools can be undertaken systematically and successfully, and so that the research objectives can be achieved afterwards accordingly. This proven by referring to the findings that gathers which shows that MAR have a significant in improving the achievement of the students in the topic of Chemical Bond. For further action, the study on the effectiveness of the developed MAR will be conducted to investigate its influence towards visualization skill. This application will be tested within future studies, in order to determine the effectiveness of the developed tools.

\section{Acknowledgement}

The authors would like to thank Universiti Teknologi Malaysia and Ministry of Higher Education Malaysia for their support in making this project possible. This work was supported by the Research University Grant (Q.J130000.2531.16H59) initiated by Universiti Teknologi Malaysia and Ministry of Higher Education 


\section{$7 \quad$ References}

[1] Uzuntiryaki, E., \& Geban, Ö. (2005). Effect of conceptual change approach accompanied with concept mapping on understanding of solution concepts. Instructional Science, 33, 311-339. https://doi.org/10.1007/s11251-005-2812-z

[2] Eggen, P. and Kauchak, D. (2004). Educational Psychology: Windows on Classrooms. Upper Saddle River: Pearson Prentice Hall.

[3] Marshall, H. A. (2003). Countering Astronomy Misconceptions in High School Students.

[4] Bahar, M. (2003). Misconceptions in biology education and conceptual change strategies. Educational Science: Theory \& Practice, 55-64.

[5] Palmer, D. (2001). Students' alternative conceptions and scientifically acceptable conceptions about gravity. International Journal of Science Education, 23(7), 691-706. https://doi.org/10.1080/09500690119453

[6] Nakiboglu, C., \& Tekin, B. B. (2006). Identifying Students' Misconceptions about Nuclear Chemistry. A Study of Turkish High School Students. Journal of Chemical Education, 83(11), 1712-1718. https://doi.org/10.1021/ed083p1712

[7] Stefani, C., \& Tsaparlis, G. (2009). Students' levels of explanations, models, and misconceptions in basic quantum chemistry: A phenomenographic study. Journal of Research in Science Teaching, 46(5), 520-536. https://doi.org/10.1002/tea.20279

[8] Duis, J. M. (2011). Organic Chemistry Educators' Perspectives on Fundamental Concepts and Misconceptions: An Exploratory Study.Journal of Chemical Education88(3).

[9] Nahum, T. L., Hofstein, A., Mamlok-naaman, R., \& Bar-dov, Z. (2004). Can Final Examinations Amplify Students' Misconceptions in Chemistry?Chemistry Education Research and Practice, 5(3), 301-325. https://doi.org/10.1039/b4rp90029d

[10] Daniel, K. C., Khang, N., \& Sai, L. (2001). Alternative Conceptions of Chemical Bonding. Journal of Science and Mathematics Education in S.E. Asia, (2), 40-50.

[11] Mohd Nor, B., and A. Nur Afza. "Pendidikan di Malaysia memupuk budaya sains dan teknologi dengan memberi tumpuan kepada perkembangan individu yang kompetitif, dinamik, tegas dan berdaya tahan serta dapat menguasai ilmu sains dan berketrampilan teknologi." Universiti Teknologi Malaysia. E-Print UTM. https://doi.org/10.7186/ bgsm 56201017

[12] Sanger, M. J., \& Badger, S. M. (2001). Using Computer-Based Visualization Strategies to Improve Students' Understanding of Molecular Polarity and Miscibility, 78(10). https://doi.org/10.1021/ed078p1412

[13] Taber, K. S. (2009). Challenging Misconceptions in the Chemistry Classroom : Resources to Support Teachers, 13-20.

[14] Jones, K. O., Harland, J., Reid, J. M. V, \& Bartlett, R. (2009). Relationship Between Examination Questions and Bloom's Taxonomy. 39th ASEE/IEEE Frontiers in Education Conference. https://doi.org/10.1109/fie.2009.5350598

[15] Mirzaie, R. A., Shahmohammadi, M., \& Kouhi, A. (2010). Study of students' mental images effect on learning chemistry. Eurasian Journal on Physics and Chemistry Education, 2(1), 53-62.

[16] Halim, N.D.A., Ali, M.B., Junaidi, J., Yahaya, N. (2010). Learning acids and bases through inquiry based website. 2010 IEEE Conference on Open Systems (ICOS 2010) pp. 51-56 2010. https://doi.org/10.1109/icos.2010.5720063

[17] Vavra, K. L., Janjic-Watrich, V., Loerke, K., Phillips, L. M., Norris, S. P., \& Macnab, J. (2011). Visualization in Science Education. Alberta Science Education Journal , 22-30. 
[18] Shelton, B. E., \& Hedley, N. R. (2002). Using Augmented Reality for Teaching Earth-Sun relationships to Undergraduate Geography Students. In Augmented Reality Toolkit, the First IEEE International Workshop (pp. 8-pp). https://doi.org/10.1109/art.2002.1106948

[19] FitzGerald, E., Ferguson, R., Adams, A., Gaved, M., Mor, Y., \& Thomas, R. (2013). Augmented reality and mobile learning: the state of the art. International Journal of Mobile and Blended Learning, 5(4), 43-58. https://doi.org/10.4018/ijmbl.2013100103

[20] Yunos, M. A. A. M., Atan, N. A., Said, M. N. H. M., Mokhtar, M., \& Samah, N. A. (2017). Collaborative Learning in Authentic Environment Apps to Promote Preschool Basic Scientific Process Skills. International Journal of Interactive Mobile Technologies (iJIM), 11(3), 4-15. https://doi.org/10.3991/ijim.v11i3.5774

[21] Al-fahad, F. N. (2009). Students' Attitudes And Perceptions Towards The Effectiveness Of Mobile Learning In King Saud University, Saudi Arabia, 8(2).

[22] Chee, K. N., Yahaya, N., Ibrahim, N. H., \& Hasan, M. N. (2017). Review of mobile learning trends 2010-2015: a meta-analysis. Journal of Educational Technology \& Society, 20(2), 113-126.

[23] Oostveen, R., Muirhead, W., \& Goodman, W. M. (2011). Tablet PCs and reconceptualizing learning with technology: a case study in higher education. Interactive Technology and Smart Education, 8(2), 78-93. https://doi.org/10.1108/17415651111141803

[24] Ismail, N. S., Harun, J., Zakaria, M. A. Z. M., \& Salleh, S. M. (2017, April). The Effect of Mobile Problem-Based Science Dictionary Application DicScience PBL towards Students' Mastery of Scientific Terms and Critical Thinking. In Learning and Teaching in Computing and Engineering (LaTICE), 2017 International Conference on (pp. 69-75). IEEE. https://doi.org/10.1109/latice.2017.19

[25] Mayer, R. E. (2001). Multi-media Learning. New York: Cambridge University Press.

[26] Wu, H. K., Shah, P. (2004). Exploring visuospatial thinking in chemistry learning. Science Education 88, no 3 (May): 465-92.

[27] Mayer, R. E., \& Moreno, R. (2002). Animation as an Aid to Multimedia Learning.Educational psychology review, 14(1), 87-99.

[28] Baddeley, A. D. (1986). Working Memory.New York: Oxford University Press.

[29] Paivio, A. (1986). Mental Representations: A Dual Coding Approach. New York: Oxford University Press.

[30] Sweller, J. (1999). Instructional Design in Technical Areas. Camberwell, Australia: ACER Press.

[31] Mayer, R. E. Moreno, R., Boire, M., and Vagge, S. (1999). Maximizing Constructivist Learning From Multimedia Communications by Minimizing Cognitive Load.Journal ofEducational Psychology, 91, 638-643. https://doi.org/10.1037//0022-0663.91.4.638

[32] Mayer, R. E. (2005). Principles for Reducing Extraneous Processing in Multimedia Learning: Coherence, Signaling, Redundancy, Spatial Contiguity, and Temporal Contiguity Principles. The Cambridge handbook of multimedia learning, 183-200. https://doi.org/10.1017/cbo9780511816819.013

[33] Shariffudin, S. R., Azanan, S., \& Hsien, G. J. (2012). Multiple Intelligence Multimedia Courseware (Mimco) Based on the Constructivist-Contextual Model for the Learning of Some Chemistry Concepts. International Journal of Future Computer and Communication, 1(1), 29-31. https://doi.org/10.7763/ijfcc.2012.v1.9

[34] Ibrahim, M., Antonenko, P. D., Greenwood, C. M., \& Wheeler, D. (2012). Effects of segmenting, signaling, and weeding on learning from educational video.Learning, Media and Technology, 37(3), 220-235. https://doi.org/10.1080/17439884.2011.585993

[35] Sorden, S. (2012). The cognitive theory of multimedia learning. Handbook of educational theories. Charlotte, NC: Information Age Publishing. 


\section{Authors}

Nor Farhah Saidin is a PhD student on Educational Technology at Faculty of Education, Universiti Teknologi Malaysia, 81310 Skudai, Johor, Malaysia. (email: farhahsaidin@gmail.com).

Noor Dayana Abd Halim is a senior lecturer at Department of Educational Science, Mathematics and Creative Multimedia, Faculty of Education, Universiti Teknologi Malaysia, 81310 Skudai, Johor, Malaysia (noordayana@utm.my)

Noraffandy Yahaya is a associate professor at Department of Educational Science, Mathematics and Creative Multimedia, Faculty of Education, Universiti Teknologi Malaysia, 81310 Skudai, Johor, Malaysia (p-afandy@,utm.my)

Article submitted 2019-04-27. Resubmitted 2019-06-04. Final acceptance 2019-06-17. Final version published as submitted by the authors 